\title{
Assessment of Character Strengths
}

Lisa Wagner (http://orcid.org/0000-0002-1925-2676)

Willibald Ruch (http://orcid.org/0000-0001-5368-3616)

University of Zurich

\section{Author Note}

Disclosure statement: The second author is a Senior Scientist for the VIA Institute on Character, which holds the copyright to the VIA Inventory of Strengths.

\section{This is a preprint version of a chapter accepted for publication:}

Wagner, L. \& Ruch, W. (in press). Assessment of character strengths. In W. Ruch, A. B.

Bakker, L. Tay, \& F. Gander (Eds.), Handbook of positive psychology assessment. Hogrefe. 


\section{Assessment of character strengths}

Character strengths are among the most frequently studied research topics in positive psychology (Donaldson et al., 2015). This chapter briefly introduces the VIA classification of character strengths and virtues (Peterson \& Seligman, 2004) and discusses some general considerations when assessing character strengths. We then focus on reviewing different instruments that have been used to assess character strengths across different age groups and contexts. Overall, we aim to provide an overview of the instruments available and the challenges that go along with assessing character strengths.

\section{Introduction: Character strengths}

As a result of a multi-year collaborative project, Christopher Peterson and Martin Seligman published "Character Strengths and Virtues: A Handbook and Classification" in 2004, presenting the VIA classification of character strengths and virtues. The VIA classification aimed to provide a framework for describing positively valued traits that are believed to contribute to a "good life." In creating this framework, Peterson and Seligman (2004) considered a wide range of sources, such as virtue lists from various world religions and philosophical traditions, developmental theories, youth programs and organizations, as well as other sources, ranging from literature to popular culture.

To select character strengths, a set of criteria was used, most of which had to be met. These criteria included the following: A strength should (1) contribute to fulfillments that constitute the "good life," both for the individual and for other people, (2) be morally valuable in its own right (see Stahlmann \& Ruch, 2020), (3) not demean others when displayed, (4) not have an opposite term that could also be seen as a strength (see Seligman, 2015), (5) be manifested in thoughts, feelings, and actions and consequently be measurable, and (6) be sufficiently distinct from all other strengths in the classification. Moreover, each character strength should have (7) universally recognized paragons, (8) prodigies (see Park \& 
Peterson, 2006a), and (9) "imbeciles" who do not display the strength at all, and lastly, (10) societies should have institutions and rituals that are aimed at promoting the character strength. In later publications, twelve criteria were listed (see discussion in Ruch \& Stahlmann, 2019). The VIA classification (Peterson \& Seligman, 2004) is shown in Table 1.

\section{Relevant definitions}

The VIA classification assigned the 24 character strengths to six core virtues (see Table 1). These core virtues resulted from reviewing various philosophical and religious traditions across time and place (Dahlsgaard et al., 2005). On a hierarchically lower level, situational themes are described. In this chapter, we define the relevant constructs of the VIA classification (Peterson \& Seligman, 2004) as follows:

- Character strengths are positively valued traits that contribute to "the good life" for an individual and others ${ }^{1}$

- Virtues are core characteristics that have been described and valued by both moral philosophers and religious thinkers across time and cultures

- Situational themes are habits that allow individuals to display a certain character strength in a specific situation

Peterson and Seligman (2004) argue that virtues are too abstract to be assessed in individuals. While ad-hoc measures based on the descriptions of the virtues (e.g., Ruch, Heintz et al., 2020) or on items assessing character strengths (e.g., McGrath, 2019) exist for research purposes, it is not recommended to use these for other purposes. We are not aware of instruments designed specifically for assessing situational themes; thus, we will focus on the assessment of character strengths in the following.

\footnotetext{
${ }^{1}$ In their handbook, Peterson and Seligman define character strengths as "the psychological ingredientsprocesses or mechanisms-that define the virtues. Said another way, they are distinguishable routes to displaying one or another of the virtues (Peterson \& Seligman, 2004, p. 13)." On page 4 of their handbook, Peterson and Seligman (2004) also provide the description that character strengths "make the good life possible." For assessment purposes, it seems that a more operational definition would be helpful, which we provide here.
} 


\section{Table 1}

VIA-Classification of Character Strengths and Virtues

1. Wisdom and knowledge - Cognitive strengths that entail the acquisition and use of knowledge.

- Creativity [originality, ingenuity]: Thinking of novel and productive ways to conceptualize and do things; includes artistic achievement but is not limited to it

- Curiosity [interest, novelty-seeking, openness to experience]: Taking an interest in ongoing experience for its own sake; finding subjects and topics fascinating; exploring and discovering

- Judgment [critical thinking]: Thinking things through and examining them from all sides; not jumping to conclusions; being able to change one's mind in light of evidence; weighing all evidence fairly

- Love of Learning: Mastering new skills, topics, and bodies of knowledge, whether on one's own or formally; obviously related to the strength of curiosity but goes beyond it to describe the tendency to add systematically to what one knows

- Perspective [wisdom]: Being able to provide wise counsel to others; having ways of looking at the world that make sense to oneself and to other people

2. Courage - Emotional strengths that involve the exercise of will to accomplish goals in the face of opposition, external or internal

- Bravery [valor]: Not shrinking from threat, challenge, difficulty, or pain; speaking up for what is right even if there is opposition; acting on convictions even if unpopular; includes physical bravery but is not limited to it

- Perseverance [persistence, industriousness]: Finishing what one starts; persisting in a course of action in spite of obstacles; "getting it out the door"; taking pleasure in completing tasks

- Honesty [authenticity, integrity]: Speaking the truth but more broadly presenting oneself in a genuine way and acting in a sincere way; being without pretense; taking responsibility for one's feelings and actions

- Zest [vitality, enthusiasm, vigor, energy]: Approaching life with excitement and energy; not doing things halfway or halfheartedly; living life as an adventure; feeling alive and activated

3. Humanity - Interpersonal strengths that involve tending and befriending others

- Love: Valuing close relations with others, in particular those in which sharing and caring are reciprocated; being close to people

- Kindness [generosity, nurturance, care, compassion, altruistic love, "niceness"]: Doing favors and good deeds for others; helping them; taking care of them

- Social intelligence [emotional intelligence, personal intelligence]: Being aware of the motives and feelings of other people and oneself; knowing what to do to fit into different social situations; knowing what makes other people tick

4. Justice - Civic strengths that underlie healthy community life

- Teamwork [citizenship, social responsibility, loyalty]: Working well as a member of a group or team; being loyal to the group; doing one's share

- Fairness: Treating all people the same according to notions of fairness and justice; not letting personal feelings bias decisions about others; giving everyone a fair chance 
- Leadership: Encouraging a group of which one is a member to get things done and at the time maintain time good relations within the group; organizing group activities and seeing that they happen

5. Temperance - Strengths that protect against excess

- Forgiveness: Forgiving those who have done wrong; accepting the shortcomings of others; giving people a second chance; not being vengeful

- Humility: Letting one's accomplishments speak for themselves; not regarding oneself as more special than one is

- Prudence: Being careful about one's choices; not taking undue risks; not saying or doing things that might later be regretted

- Self-regulation [self-control]: regulating what one feels and does; being disciplined; controlling one's appetites and emotions

6. Transcendence - Strengths that forge connections to the larger universe and provide meaning.

- Appreciation of beauty and excellence [awe, wonder, elevation]: Noticing and appreciating beauty, excellence, and/or skilled performance in various domains of life, from nature to art to mathematics to science to everyday experience

- Gratitude: Being aware of and thankful for the good things that happen; taking time to express thanks

- Hope [optimism, future-mindedness, future orientation]: Expecting the best in the future and working to achieve it; believing that a good future is something that can be brought about

- Humor [playfulness]: Liking to laugh and tease; bringing smiles to other people; seeing the light side; making (not necessarily telling) jokes: liking to laugh and joke; bringing smiles to other people

- Spirituality [faith, purpose]: Having coherent beliefs about the higher purpose and meaning of the universe; knowing where one fits within the larger scheme; having beliefs about the meaning of life that shape conduct and provide comfort

(C) Copyright 2004-2021. VIA Institute on Character. All Rights Reserved. Used with Permission. Www.viacharacter.org

\section{Relevance: Why should character strengths be assessed?}

From a research perspective, we need sound measures of character strengths to empirically study their relationship with indicators of the "good life" (first criterion described by Peterson and Seligman, 2004). In addition, of course, it is also relevant to study their relationships with related constructs, such as the five-factor model of personality (e.g., McGrath et al., 2020). However, next to their relevance for advancing research in positive psychology (Donaldson et al., 2015), character strengths are also assessed in many practical contexts. These contexts include, but are not limited to, psychotherapy (e.g., Chaves et al., 
2019; Flückiger \& Beesdo-Baum, 2020), vocational counseling (e.g., Littman-Ovadia et al., 2014), coaching (e.g., Burke \& Passmore, 2019), education (e.g., Norrish et al., 2013) and finally, character strengths-based positive psychological interventions (e.g., Niemiec, 2017; Ruch, Niemiec et al., 2020). The specific relevance might vary across different fields. Still, in many cases, the main function of assessing character strengths in practice can be described as resource activation (see Flückiger \& Beesdo-Baum, 2020). Character strengths are typically assessed to enable individuals to recognize strengths in themselves and then work with these strengths in a coaching or therapy process.

\section{General considerations in the assessment of character strengths}

Before we review the different instruments for assessing character strengths, some general questions on to the assessment of character strengths deserve mention. These questions include: Is social desirability of particular relevance when character strengths are assessed? Should measures of character strengths be scored normatively or ipsatively? Which aspects of character strengths are assessed next to their trait levels?

\section{Role of social desirability}

Given the positive and morally valued nature of character strengths (Stahlmann \& Ruch, 2020), researchers and practitioners might be concerned about the potential influence of a self-enhancement bias created by the character strengths' social desirability on the results obtained. In the past, researchers have relied on scales assessing social desirability to determine the extent to which self-enhancement tendencies influence the scores obtained on personality questionnaires. When using such a scale together with the VIA-IS, between two (Peterson and Seligman, 2004: prudence and spirituality) and five (Macdonald et al., 2008: curiosity, honesty, fairness, kindness, forgiveness) character strengths showed correlations of at least $r=.30$ to a social desirability scale. Overall, the size of the correlations did not differ from a measure of five-factor-model personality traits also used by Macdonald et al. (2008). 
Ruch, Proyer, Harzer et al. (2010) concluded that social desirability is not a strong threat to the validity of the scores obtained by the VIA-IS. This conclusion is based on small correlations between the Lie Scale of the Eysenck Personality Questionnaire-Revised (Eysenck \& Eysenck, 1991) and the VIA-IS scales (using self-, median $r=.06$, and informant ratings, median $r=.06$ ), as well as on a low correlation between a derived desirability index (difference between self and informant rating) and the Lie scale (median $r=.05$ ). Still, the correlation for prudence and teamwork were noteworthy and need to be considered. As "lie" items often contain virtuous behaviors, it is, more likely that substance is responsible for these correlations and not only response style. This idea is also supported by work on impression management or social desirability scales (see, e.g., Zettler et al., 2015).

Another frequently used operationalization of self-enhancement is the discrepancy between self- and informant reports (e.g., Müller \& Moshagen, 2019). One might assume that the discrepancy between both should be larger for ratings strongly affected by social desirability. For both VIA-IS and the VIA-Youth, median self-informant correlations around .40 have been reported (Ruch, Proyer, Harzer et al., 2010; Ruch, Weber et al., 2014). These values are highly comparable to coefficients obtained for other, not explicitly positively valued, personality traits (for a meta-analysis, see e.g., Connelly \& Ones, 2010). Of note, if any differences were observed, informants typically gave (at least descriptively) higher ratings than self-raters (e.g., Ruch, Proyer, Harzer et al., 2010). This observation suggests that the desirable nature of character strengths does not lead self-reports to be disproportionally inflated by self-enhancement.

\section{Ipsative vs. normative scoring and assessing signature strengths}

While in most research studies, a normative approach to scoring measures of character strengths has been applied, ipsative scoring is relevant to many practical contexts. In many settings, it is not the most relevant to know how a person scores compared to others, but 
rather which character strengths are ranked highest within an individual. Also, many strengths-based interventions build on so-called signature strengths. Signature strengths are those character strengths that are highly typical of an individual and whose display is rewarding (Peterson \& Seligman, 2004), not unlike Allport's (1961) notion of personal traits. Peterson and Seligman (2004) claimed individuals have three to seven of these strengths. However, empirical studies show that while the mean is typically between five and six, the number of signature strengths individuals identify with varies widely (Blanchard et al., 2020; McGrath, 2019).

At least in some character strengths-based interventions, individuals complete the VIA-IS or the VIA-Youth to identify their most pronounced strengths. Then, they are asked to display one (e.g., Seligman et al., 2005), three (e.g., Toback et al., 2016), four (e.g., Harzer \& Ruch, 2016), or five (e.g., Proyer et al., 2015) of these highest-ranking character strengths in new ways. Overall, though, there is very little evidence that it makes a difference whether the strengths used in an intervention are among the top or the bottom in an individuals' rank order of strengths (see Proyer et al., 2015). In addition, instruments intending to assess the individual's level of each of the character strengths and instruments intending to assess signature strengths directly only converge modestly with each other (Blanchard et al., 2020: McGrath, 2019). This finding suggests that what individuals consider their signature strengths is not directly aligned with what character strengths measures assess. As a consequence, it seems useful to always include an individual's perception when determining signature strengths.

Given that the items across all scales of the VIA-IS were not constructed to be of the same psychometric difficulty, it would also seem useful to norm any data before providing an individual's rank order of character strengths. Such a procedure is done by some platforms 
that allow individuals to complete the VIA-IS online and to receive personal feedback (e.g., the German-speaking site www.charakterstaerken.org), but by far not in all cases.

Relatedly, some research articles make statements such as "the highest strengths in this group of people (for instance, a certain profession) are X, Y, and Z" when comparing the means across all 24 character strengths within this group. Such statements are not particularly meaningful in light of varying psychometric difficulty across the scales. Of course, it is possible to compare the rank order or the means of strengths between different groups but making claims about the rank order within one group without comparisons seems problematic. Thus, comparisons among character strengths should always be based on normed data. Normative data for the US have recently been published (McGrath et al., 2021).

\section{Assessing the application of character strengths in different life domains}

Even if two individuals can be characterized by the same level of a given character strength, such as creativity, we would not expect both individuals to show the same level of creative behavior in their workplaces. The idea of differentiating between the "possession" or "endorsement", on the one hand, and the "use", "application", "display" or "deployment" of character strengths, on the other hand, has led to the development of several scales that capture this aspect. Generic measures of strengths use, such as the Strengths Knowledge Scale and the Strengths Use Scale (Govindji \& Linley, 2007), are independent of a specific understanding of strengths. Such scales assess "strengths" without restricting respondents' understanding of what "strengths" to consider (the items refer to "my strengths" and "things I am good at"). As a consequence, individuals will vary greatly in the traits they include in this very broad definition. It is thus not surprising that strengths use correlates highly with selfesteem and self-efficacy (e.g., Govindji \& Linley, 2007): It describes whether a person perceives opportunities to do what they think they are good at and whether they believe they show these behaviors; recent research has shown that two dimensions that underly the scores 
in the Strengths Use Scale can be distinguished: (1) perceiving many opportunities to display one's strengths and (2) displaying strengths-related behavior (van Zyl et al., 2021).

These two aspects have also been considered when explicitly using the VIA classification (Peterson \& Seligman, 2004) as framework for assessing character strengths. It is both of interest to assess the extent to which individuals (1) perceive their environment as conducive to displaying behavior in accordance with one's character strengths and (2) show character strengths-related behaviors. Harzer and Ruch (2013) define the applicability of a character strength as "the degree to which situational circumstances allow an individual to display strengths-relevant behavior" (p. 967). The applicability of strengths has been assessed to complement an individual's level of a given character strength. Individuals within the same workplace showed a relatively strong inter-rater agreement regarding the aspects that relate to perceived characteristics of a workplace (i.e., the degree to which a given character strength is demanded and helpful; Harzer \& Ruch, 2013). Thus, it is reasonable to assume that these ratings indeed relate to characteristics of the (work) environment.

The life domains assessed have also been extended beyond work and studies (Kachel et., 2020) to include domains such as leisure, romantic relationships, or close personal relationships (Wagner et al., 2021), and it has been suggested to separate the items relating to the strengths' relevance in a given environment (i.e., "it is demanded," "it is helpful," and "it is important to me") from the item relating to behavior (i.e., "I do it"). The ACS-RS has also been adapted for use with adolescents in the context of school (Wagner \& Ruch, 2021). In this version, only one external ("it is desired") and one internal aspect ("I behave this way") is rated for each character strength.

\section{Assessing the "underuse" and "overuse" of character strengths}

By offering a systematic description of positive individual traits, Peterson and Seligman (2004) view the VIA classification as a positive counterpart to classifications that 
describe mental illness, such as the Diagnostic and Statistical Manual of Mental Disorders (DSM; American Psychiatric Association, 2013). There are also attempts to characterize mental illnesses by the opposite, the absence or the excess of the 24 character strengths (Seligman, 2015). One attempt to assess the under- and overuse (roughly corresponding to absence and excess) of character strengths is the Overuse/ Underuse/Optimal Use inventory of strengths (OUOU; Freidlin et al., 2017). The OUOU asks participants to consider three socalled facets (underuse, optimal use, and overuse) of each of the 24 character strengths and allocate $100 \%$ among the three facets for each respective strength. For example, the overuse of love of learning is described as "I seek knowledge so much that this negatively impacts my relationships or my work/school."

This approach has certain drawbacks. Namely, the three answers for each character strength are not independent (in fact the answers to one facet are depending on the answers to the other two facets), and, therefore, no comparisons between individuals regarding their level of character strengths can be made. Also, the validity of the OUOU can be questioned. In particular, the is no documentation on how the conceptualizations of under- and overuse have been constructed or validated. Is there only one type of over- and underuse or more different ones, that also may relate to different pathologies? There is also no evidence that the level of a character strength is related to underuse, optimal use, and, especially, to overuse. Such evidence would be important to support the claim that the same construct (namely, the same character strength) is underlying all three facets. Previous studies on single character strengths have also failed to identify the suggested "too much of a good thing" (e.g., Ruch, Proyer, \& Weber, 2010; Wiese et al., 2017; see Ng \& Tay, 2020, for a discussion) and have rather found a linear relationship between character strengths and well-being. In addition, Freidlin et al. (2017) report a relatively high internal consistency $(\alpha=.75)$ for the 24 items assessing the overuse of all character strengths. This finding is somewhat surprising as one 
would expect that individuals show overuse of specific character strengths and not of all character strengths at the same time.

One might draw a parallel to other debates on the assessment of positively valued constructs, such as the question of whether one can value happiness "too much" (Mauss et al., 2011). As demonstrated by Luhmann et al. (2016), for the case of the Valuing Happiness Scale (Mauss et al., 2011), correlations with negative outcomes can be artifacts of the negative wording of a few items. Considering the example item mentioned above, it is not surprising that the perception that one's behavior impacts life domains negatively is related to negative outcomes.

In light of these considerations and open questions, theoretical interpretations do not seem warranted before the scale has been systematically validated. One could also argue that the criteria put forward to describe character strengths do not apply to the overuse of strengths; hence it cannot be an expression of character strengths. Overall, it seems that a construct such as "overuse" of a trait cannot be described as an expression of a character strength at a high level but rather as a construct separate from character strengths, which is related to a generally negative self-evaluation.

\section{Overview of instruments assessing character strengths}

Table 2 gives an overview of commonly used instruments for the assessment of character strengths. This overview is structured by the target group (adults vs. children/adolescents). It first describes the standard instruments, then several shorter forms, and finally, instruments assessing specific aspects of character strengths (i.e., signature strengths, application of character strengths in different life domains, and over-/underuse of character strengths). This overview is by no means comprehensive. In particular, it does not include measures that used the VIA Classification as a starting point for their construction but assess traits beyond the 24 character strengths (e.g., CIVIC, $\mathrm{Ng}$ et al., 2018) nor instruments 
that were only presented by Peterson and Seligman (2004) in their handbook, but never published or validated beyond it (e.g., the VIA-Structured Interview for the assessment of signature strengths or the VIA Rising to the Occasion Inventory, which asks participants to reflect on their behavior in specific strengths-relevant situations). Thus, Table 2 does not represent a complete overview of all existing measures of character strengths. 


\section{Table 2}

Psychometric Properties of Prevalent Instruments Assessing Character Strengths (Sorted Chronologically By Category)

\begin{tabular}{|c|c|c|c|c|c|}
\hline Instrument & $\begin{array}{l}\text { Informant and } \\
\text { number of items }\end{array}$ & Reliability & (Convergent) Validity & Languages available & Notes \\
\hline \multicolumn{6}{|l|}{ Adults } \\
\hline $\begin{array}{l}\text { VIA Inventory } \\
\text { of Strengths } \\
\text { (Peterson \& } \\
\text { Seligman, 2004) }\end{array}$ & $\begin{array}{l}\text { Self-ratings } \\
\text { ( } 240 \text { items; } 10 \text { items } \\
\text { per strength) }\end{array}$ & $\begin{array}{l}\alpha \mathrm{s}=>.70 \\
r_{\mathrm{tt}}=>.70 \text { (4 months) } \\
\text { (Peterson et al., 2004) } \\
\alpha \mathrm{s}=.71-.90 \\
\text { (median } \alpha=.76) \\
r_{\mathrm{tt}}=.69-.87 \\
\text { (over } 3 \text { months) } \\
r_{\mathrm{tt}}=.65-.85 \\
\text { (over } 6 \text { months) } \\
r_{\mathrm{tt}}=.62-.85 \\
\text { (over 9 months) } \\
\text { (Ruch, Proyer, Harzer } \\
\text { et al., 2010) }\end{array}$ & $\begin{array}{l}\text { With informant-rating } \\
r=.26-.69 \text { (mean } r=.42 \text { ) } \\
\text { (Ruch, Proyer, Harzer et al., } \\
\text { 2010) }\end{array}$ & $\begin{array}{l}\text { Afrikaans, Arabic, } \\
\text { Chinese (Simplified), } \\
\text { Chinese (Traditional), } \\
\text { Croatian, Danish, } \\
\text { Dutch, French, } \\
\text { German, Greek, } \\
\text { Hebrew, Hindi, } \\
\text { Italian, Japanese, } \\
\text { Korean, Portuguese } \\
\text { (Brazil), Portuguese } \\
\text { (Portugal), Russian, } \\
\text { Spanish, Swedish, } \\
\text { Turkish, Urdu, see } \\
\text { supplementary Table } \\
\text { S2 for an overview of } \\
\text { published adaptations } \\
\text { (https://osf.io/2rzj3/ ) }\end{array}$ & \\
\hline $\begin{array}{l}\text { VIA-IS-R } \\
(\text { McGrath, } \\
2019)^{2}\end{array}$ & $\begin{array}{l}\text { Self-ratings } \\
\text { (192 items; } 8 \text { items per } \\
\text { strength) }\end{array}$ & $\begin{array}{l}\alpha \mathrm{s}=.77-.91 \text { (median } \\
\alpha=.85) \\
(\text { McGrath, 2019) }\end{array}$ & $\begin{array}{l}\text { With VIA-IS-120 } \\
r=.59-.94(\text { mean } r=.83)\end{array}$ & English & $\begin{array}{l}\text { Data from a sample } \\
\text { demographically } \\
\text { representative of }\end{array}$ \\
\hline
\end{tabular}

${ }^{2}$ The VIA Assessment Suite (McGrath, 2019) also contains several additional versions: VIA Inventory of Strengths-M (VIA-IS-M; containing the 96 items of the VIA-IS-R with the highest item-total correlations); VIA Inventory of Strengths-P (VIA-IS-P; 96 items, exclusively positively-keyed items), Global Assessment of Character Strengths72 (GACS-72; three items per strength to assess its similarity to a signature strength), and Global Assessment of Character Strengths - 24 (GACS-24; version of the GAS-24 with one item per strength). 


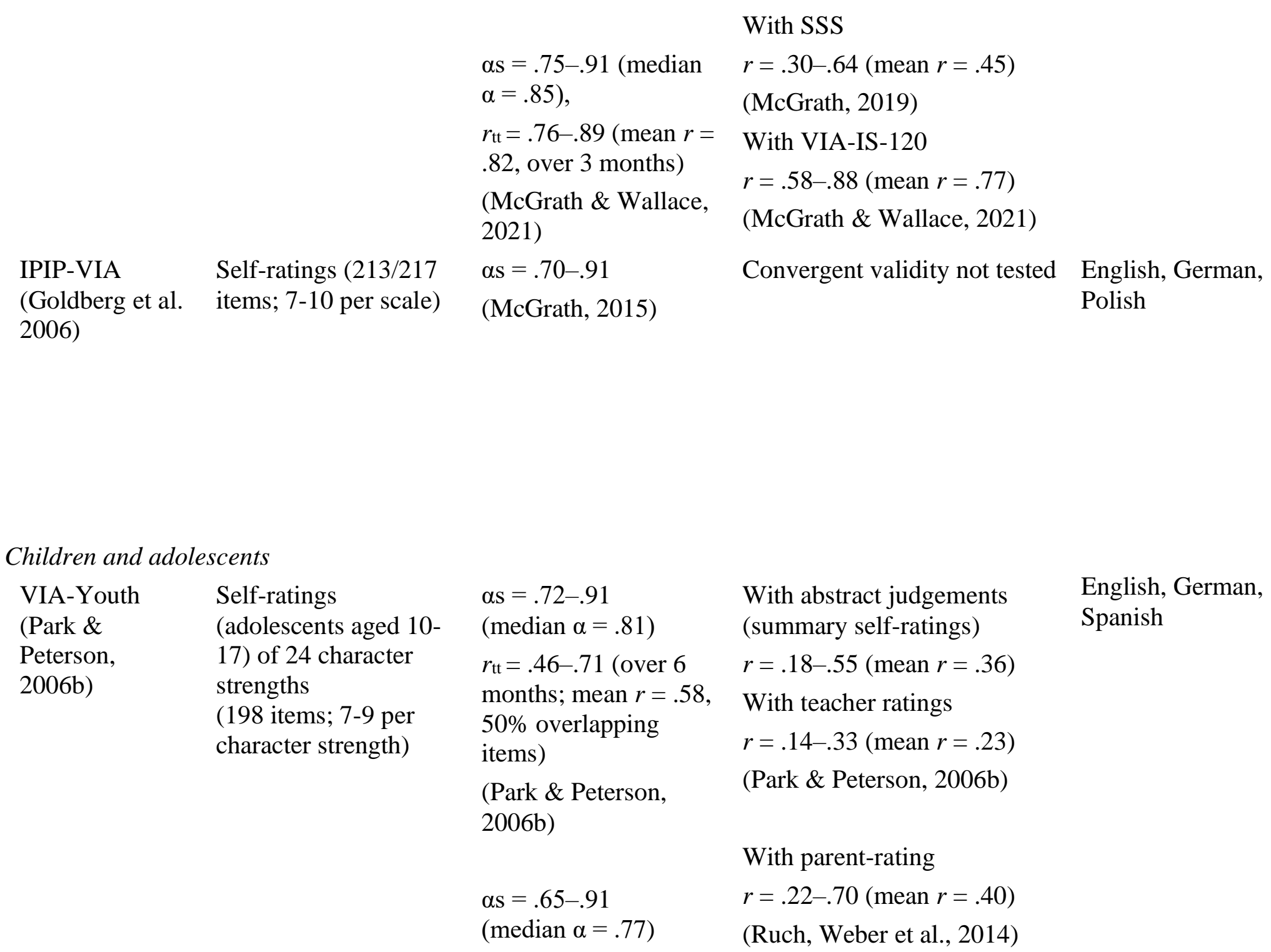

the U.S. population available (McGrath et al., 2021)

\section{Short form}

containing 96 items used in Partsch et al. (2021)

Version derived using Rasch modelling (du Plessis \& de Bruin, 2015)

$$
\begin{aligned}
& \text { (median } \alpha=.81 \text { ) } \\
& r_{\mathrm{tt}}=.46-.71 \text { (over } 6 \\
& \text { inths; mean } r=.58 \\
& 0 \% \text { overlapping } \\
& \text { (ems) } \\
& \text { Park \& Peterson, } \\
& \text { (median } \alpha=.77 \text { ) } \\
& \text { (Ruch, Weber et al., 2014) }
\end{aligned}
$$

English, German,

Spanish 


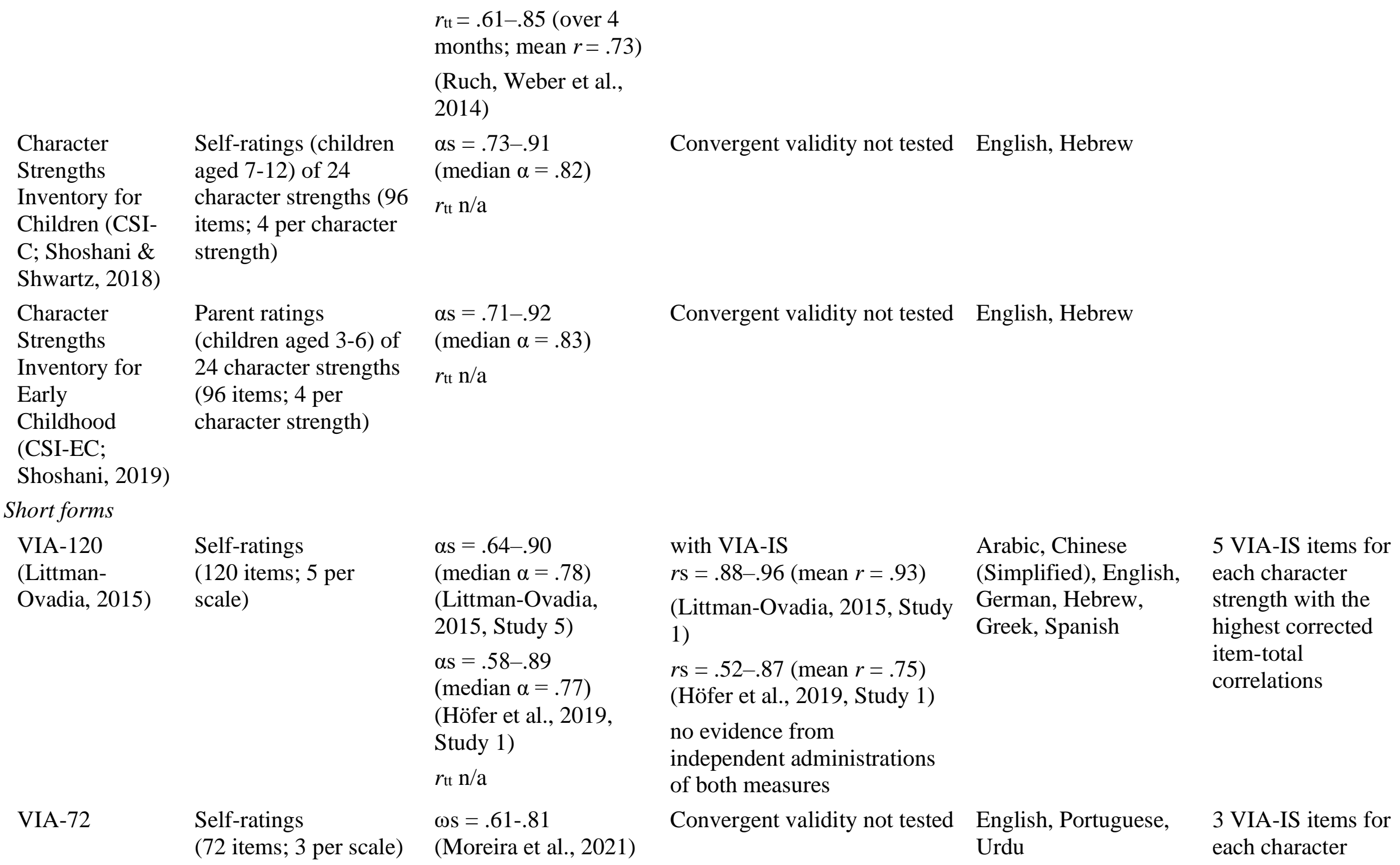




\section{$r_{\mathrm{tt}} \mathrm{n} / \mathrm{a}$}

\section{Self-rated \\ measure of \\ character \\ strengths \\ (Furnham \& \\ Lester, 2012)}

Self-ratings (24 items) $\quad r_{\mathrm{tt}} \mathrm{n} / \mathrm{a}$

\section{Character}

strengths rating

form (CSRF;

Ruch, Martínez-

Martí et al.

2014)

\section{Abbreviated}

Character

Strengths Test

(ACST:

Vanhove et al.

2016)

\section{Measures of specific aspects}

Applicability of

Character

Strengths -

Rating Scale

(ACS-RS;

Harzer \& Ruch,

2013)

Self-ratings (24 items, only 21

items/character

strengths retained after

analysis)

\section{Self-ratings of applicability (96 items in total; 4 per character strength)}

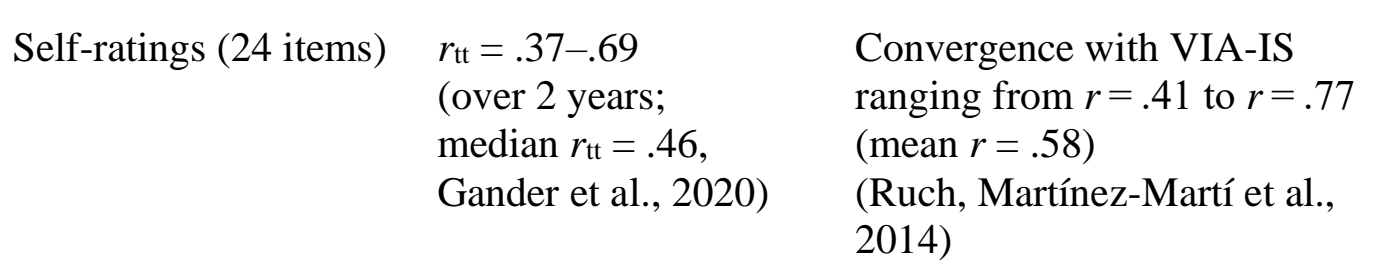

Convergence with VIA-IS

ranging from $r=.41$ to $r=.77$

(mean $r=.58$ )

(Ruch, Martínez-Martí et al., 2014)

Work life: $\alpha \mathrm{s}=.71-$ $.90($ median $\alpha=.80)$

Private life: $\alpha$ s $=.76-$ .94 (median $\alpha=.84$ )

Six virtue dimensions: $\alpha \mathrm{s}=.70-.84$

$r_{\mathrm{tt}} \mathrm{n} / \mathrm{a}$

(Harzer \& Ruch,

2013) dimensions with Big Five personality traits ranging from $r=-.27$ to $r=.54$

Median of correlations with VIA-IS: $r=.66$ for work life and $r=.70$ for private life (Harzer \& Ruch, 2013)
Convergent validity not tested

English

strength with the highest corrected item-total

correlations

Adapted for use in daily diary studies (Gander et al., 2021) and for informant ratings (Ruch, Heintz et al., 2020)

English

German

Has been adapted for use with adolescents (Wagner \& Ruch, 2021) and several life domains 


\begin{tabular}{|c|c|c|c|c|}
\hline \multirow[b]{2}{*}{$\begin{array}{l}\text { Optimal/Over/ } \\
\text { Under Used } \\
\text { Strengths } \\
\text { (OUOU; } \\
\text { Freidlin et al., } \\
\text { 2017) }\end{array}$} & & $r_{\mathrm{tt}} \mathrm{n} / \mathrm{a}$ & & \\
\hline & $\begin{array}{l}\text { Self-ratings of } \\
\text { underuse, optimal use, } \\
\text { and overuse of the } 24 \\
\text { character strengths }\end{array}$ & $\begin{array}{l}\alpha=.84 \text { underuse, } \alpha= \\
.89 \text { optimal use, } \alpha= \\
.75 \text { overuse } \\
r_{\mathrm{tt}} \mathrm{n} / \mathrm{a}\end{array}$ & Convergent validity not tested & English \\
\hline $\begin{array}{l}\text { Signature } \\
\text { Strengths } \\
\text { Survey } \\
\text { (SSS; McGrath, } \\
2019 \text { ) }\end{array}$ & $\begin{array}{l}\text { Overview of the } 24 \\
\text { character strengths, } \\
\text { participants select } \\
\text { essential strengths in } \\
\text { two rounds }\end{array}$ & $\begin{array}{l}\alpha \mathrm{n} / \mathrm{a} \\
r_{\mathrm{tt}} \mathrm{n} / \mathrm{a}\end{array}$ & $\begin{array}{l}\text { With VIA-IS-R } \\
r=.30-.64(\text { mean } r=.45) \\
\text { (McGrath, 2019) } \\
\text { With VIA-120 } \\
r=.24-.59 \text { (mean } r=.35) \\
\text { (Blanchard et al., 2020) }\end{array}$ & English \\
\hline \multicolumn{5}{|c|}{ Short forms assessing only some aspects of character strengths } \\
\hline $\begin{array}{l}\text { Chinese Virtues } \\
\text { Questionnaire } \\
\text { (CVQ-96; Duan } \\
\text { et al., 2012) }\end{array}$ & $\begin{array}{l}\text { Self-ratings of three } \\
\text { virtues (Interpersonal, } \\
\text { vitality, cautiousness) } \\
\text { (96 items; } 32 \text { items for } \\
\text { interpersonal, } 40 \text { items } \\
\text { for vitality, and } 24 \\
\text { items for cautiousness) }\end{array}$ & $\begin{array}{l}\alpha \mathrm{s}=.83-.90 \\
\text { (Duan et al., 2012) } \\
\alpha \mathrm{s}=.88-.92 \\
r_{\mathrm{tt}}=.70-.76(10 \\
\text { weeks) } \\
\text { (Duan et al., 2013) }\end{array}$ & $\begin{array}{l}\text { With Gratitude } \\
\text { Questionnaire-6 } \\
r=.27-.47 \\
\text { With Hope Scale } \\
r=.42-.52 \\
\text { (Duan et al., 2013) }\end{array}$ & Chinese \\
\hline $\begin{array}{l}\text { Brief Strengths } \\
\text { Scale-12 (BSS- } \\
12 ; \text { Ho et al., } \\
2016)\end{array}$ & $\begin{array}{l}\text { Self-ratings } \\
\text { (12 items in total; } 4 \\
\text { items each for } \\
\text { temperance strength, } \\
\text { interpersonal strength, } \\
\text { and intellectual } \\
\text { strength) }\end{array}$ & $\begin{array}{l}\alpha \mathrm{s}=.72-.89 \\
r_{\mathrm{tt}} \mathrm{n} / \mathrm{a}\end{array}$ & Convergent validity not tested & Chinese, English \\
\hline
\end{tabular}

(Wagner et al., 2021)

Answer format: Respondents are asked to distribute $100 \%$ across three facets $r=.30-.64$ (mean $r=.45$ )

(McGrath, 2019)

$r=.24-.59$ (mean $r=.35$ )

(Blanchard et al., 2020)

With Gratitude

$r=.27-.47$

strength) 


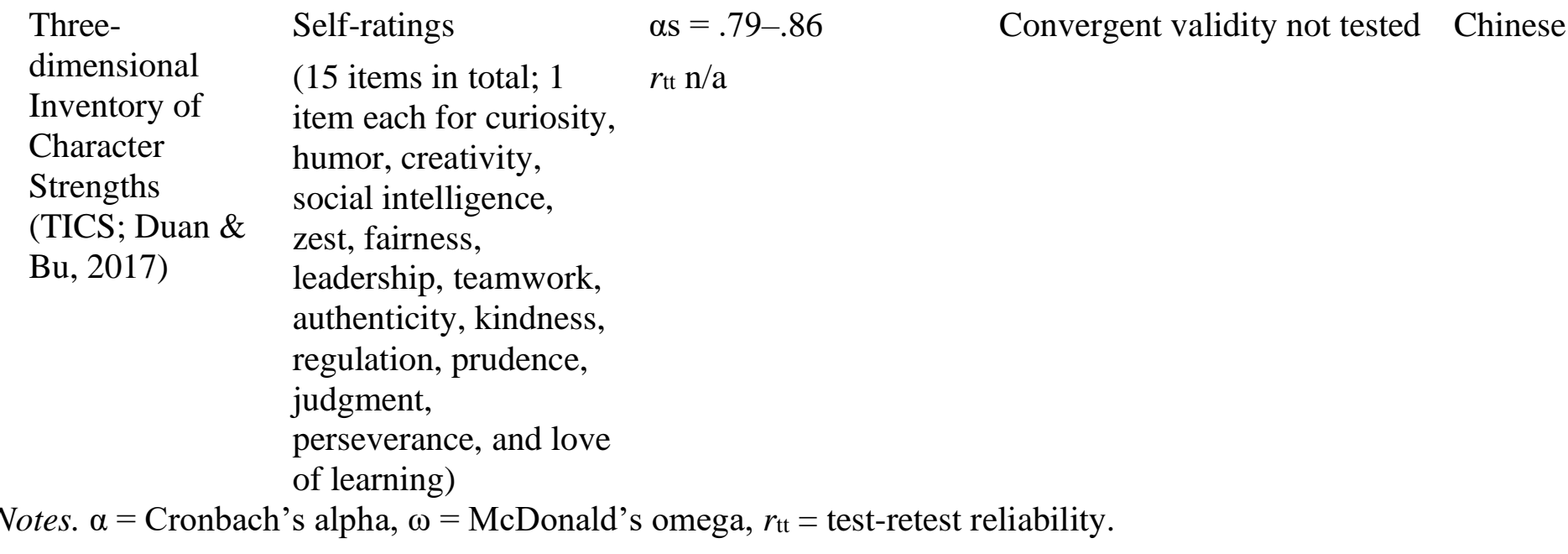




\section{Key research findings on the described measures}

For several of the measures reviewed in Table 2, only very scare validity evidence has been presented. For instance, for some of the measures, it is even unclear to which extent they converge with other established methods for assessing character strengths (convergent validity). Overall, we also know relatively little about the test-retest stability of the measures, in particular over longer time intervals. Except for the VIA-IS, the VIA-IS-R, the VIAYouth, and the CSRF, we are not aware of data on the stability. This gap in the literature should be addressed in future studies because knowledge on the test-retest stability of high relevance for evaluating the effects of interventions on character strengths. The same conclusion is true for divergent validity; for many of the measures, there is little to no evidence on their associations with conceptually overlapping or distinct constructs, such as Big Five or HEXACO personality traits (McGrath et al., 2020) or intelligence (Kretzschmar et al., 2021).

Research using the measures presented in Table 2 has mainly focused on criterion validity. For instance, the relationships with well-being (e.g., Buschor et al., 2013; Hausler et al., 2017; Wagner, Gander et al., 2020), achievement (e.g., Datu \& Bernardo, 2020; Harzer \& Ruch, 2014; Wagner, Holenstein et al., 2020), and interpersonal relationships (e.g., BoimanMeshita, \& Littman, 2021; Wagner, 2019) have been studied. To date, there is very little research considering joint and interactive effects of character strengths (for an exception, see Ruch, Platt et al., 2014), which might be a valuable avenue for future research.

\section{Studying factor structure vs. assessing virtues}

The VIA Classification was developed with a focus on the outcomes that character strengths predict. In assessment terms, this means that the focus has been on criterion validity. Even though the hierarchical structure of the classification reminds readers of factor models, it has not been conceptualized as or intended to be a factor model. That is, the 
classification - and the instruments used to assess the character strengths in the classification - were not developed with ideas about the structure of these strengths in mind. In other words, the VIA Classification was not constructed with a factorial model in mind. Instead, Peterson and Seligman (2004) describe character strengths as "distinguishable routes to displaying one or another of the virtues" (p. 13). This idea implies that an individual will not necessarily (or perhaps even rather unlikely) pursue all of those routes simultaneously, which would be implied by a factorial model (see the discussion in Ruch \& Proyer, 2015; p. 10-11). In addition, Miller (2019) argued that there are several ways in which character strengths and virtues could be related because Peterson and Seligman's (2004) descriptions have not been sufficiently clear in describing these relationships.

With these considerations in mind, it becomes evident that averaging those character strengths theoretically assigned to a virtue to form a virtue score is not meaningful. The items assessing character strengths were never constructed to assess virtues, and their contents do not reflect the descriptions of the virtues. This also means that any success or failure to show a six-factorial structure does not provide direct information on the appropriateness or validity of the VIA classification. Recently, more direct approaches to testing the assignment of character strengths to virtues (Gander et al., 2021; Giuliani et al., 2020; Ruch \& Proyer, 2015; Ruch, Heintz et al., 2020; Ruch et al., 2021) have been suggested. The results have provided relatively consistent evidence for most assignments. However, these studies have also suggested that character strengths may be assigned to more than one virtue and that the character strength of humor may be better assigned to the virtue of humanity (instead of transcendence).

Nonetheless, the higher-order structure of the instruments assessing the character strengths of the VIA classification has been addressed repeatedly. However, in many cases, items or scales had to be excluded to arrive at acceptable factor solutions; thus, many factor 
solutions do not represent all 24 character strengths. We also hasten to emphasize that while such higher-order factors describing which character strengths typically occur together might be useful for certain purposes, they hardly can be expected to represent the virtues described in the VIA Classification. A large number of solutions regarding higher-order factors that have been identified (see supplementary Table S1 available on the Open Science Framework: https://osf.io/2rzj3/). These factor solutions range from one to six factors, suggesting that there is no stable factor structure across the instruments and in most cases, also not within one instrument. This makes comparing any two results based on factor scores very difficult. Recently, McGrath (2015) and Partsch et al. (2021) have argued in favor of three-factor structures, which have shown some degree of robustness across different samples. However, the content and composition of the three factors suggested differ between the instruments (e.g., the three factors extracted from the IPIP-VIA-R by Partsch and colleagues are not comparable to those extracted from the VIA-IS or VIA-IS-R by McGrath), which makes a coherent account of how the higher-order factors should be interpreted very difficult.

Using higher-order factors of character strengths also seems of limited usefulness for many applications in research and practice. Studies often conclude that those strengths with the highest relationships to relevant criteria load onto different factors (e.g., Wagner \& Ruch, 2021). Therefore, reporting results on the level of factors may conceal the results and would not allow conclusions on the specific contributions of the single character strengths. In practice, most strengths-based interventions operate at the level of character strengths (e.g., Niemiec, 2017), as these are more concrete and arguably easier to implement than interventions based on more abstract, higher-order concepts.

\section{Equivalence between different measures}

Given the availability of different measures of character strengths that are all based on the VIA Classification, the question arises whether the scores assessed using different 
instruments can be interpreted in the same way. Several studies that address the equivalence between different character strengths measures were recently undertaken to answer this question. First, the convergence of the revised (VIA-IS-R) with the original (VIA-IS-R) questionnaire is of interest in order to determine whether the results that were obtained using one or the other questionnaire are sufficiently comparable. Using the German version of both instruments, Vylobkova et al. (2021) showed that, overall, the VIA-IS and the VIA-IS-R could be considered equivalent regarding internal consistency, correlations between the scales, as well as criterion-related validity (relationships with well-being, moral behaviors, and core virtues). Neither of the measures is clearly superior to the other in any of these criteria, and, with a few exceptions, the overlap between the homologous scales was high. McGrath and Wallace (2021) also report a high level of convergence between the different instruments within the VIA Assessment Suite (VIA-IS-R, VIA-IS-P, VIA-IS-M, GACS). We tentatively conclude from these results that results with the VIA-IS and the VIA Assessment Suite, in particular with the VIA-IS-R, can be compared.

Second, despite some differences in the structure of the instruments, it is also of interest to investigate the convergence of instruments designed for different age groups. To this end, Kretzschmar et al. (2020) used a sample of 18-year-old students who completed both the VIA-Youth and the VIA-IS, in addition to several well-being measures. The results highlighted that the two instruments assessing character strengths converged well for many strengths but less well for others (e.g., curiosity and leadership). In sum, Kretzschmar et al. (2020) considered these differences to be too large to allow comparing scores between the two instruments. Also, a meta-analysis on cross-sectional age differences in the 24 character strengths (Heintz \& Ruch, 2021) using 47 samples yielded a more substantial gap between ages 17 and 18 (i.e., the oldest group that completed the VIA-Youth and the youngest that completed in the VIA-IS) than between other age groups. Together, these findings suggest 
that making statements about which character strengths are more or less pronounced in adolescents compared to adults is not valid if such statements are based on different questionnaires in both samples.

As mentioned previously, only a moderate amount of agreement (mean $r=.45$ ) between the VIA-IS-R and the SSS has been reported (McGrath et al., 2019). To our knowledge, there are no studies directly comparing versions of the IPIP-VIA to the original version(s). Therefore, we can make no conclusions regarding their equivalence.

\section{Recommendations for instrument selection}

Assessment contexts vary in their requirements, but some general recommendations for instrument selection can be put forward. First, (very) short measures assessing character strengths with only 1 to 3 items each, such as the CSRF and the VIA-72, should only be used in large-scale studies, in which considerations of participant burden exclude the use of longer measures and in which only group-level comparisons are of interest. However, researchers should be aware that the use of these short forms comes with costs in terms of reliability and validity. Second, for the assessment in individual contexts (e.g., in counseling), we do neither recommend the use of shortened versions nor any instruments that primarily rely on factorlevel scales. Most applied work (e.g., Niemiec, 2017) focuses on the level of character strengths or is interested in identifying signature strengths. Hence, it is most informative for practitioners to use measures that allow assessing individual character strengths with sufficient reliability and validity, that is, VIA-IS, VIA-IS-R, IPIP-VIA, and VIA-Youth.

\section{References}

Allport, G. W. (1961). Pattern and growth in personality. Holt, Reinhart \& Winston. American Psychiatric Association. (2013). Diagnostic and Statistical Manual of Mental Disorders (DSM-5) (5th ed.). American Psychiatric Association. 
Blanchard, T., Kerbeykian, T., \& McGrath, R. E. (2020). Why are signature strengths and well-being related? Tests of multiple hypotheses. Journal of Happiness Studies, 21(6), 2095-2114. https://doi.org/10.1007/s10902-019-00170-2

Boiman-Meshita, M., \& Littman-Ovadia, H. (2021). Is it me or you? An actor-partner examination of the relationship between partners' character strengths and marital quality. Journal of Happiness Studies. Advance online publication. https://doi.org/10.1007/s10902-021-00394-1

Burke, J., \& Passmore, J. (2019). Strengths based coaching-A positive psychology intervention. In L. E. Van Zyl \& S. Rothmann Sr. (Eds.), Theoretical Approaches to Multi-Cultural Positive Psychological Interventions (pp. 463-475). Springer International Publishing. https://doi.org/10.1007/978-3-030-20583-6_21

Buschor, C., Proyer, R. T., \& Ruch, W. (2013). Self- and peer-rated character strengths: How do they relate to satisfaction with life and orientations to happiness? The Journal of Positive Psychology, 8(2), 116-127. https://doi.org/10.1080/17439760.2012.758305

Chaves, C., Lopez-Gomez, I., Hervas, G., \& Vazquez, C. (2019). The Integrative Positive Psychological Intervention for Depression (IPPI-D). Journal of Contemporary Psychotherapy, 49(3), 177-185. https://doi.org/10.1007/s10879-018-9412-0

Connelly, B. S., \& Ones, D. S. (2010). An other perspective on personality: Meta-analytic integration of observers' accuracy and predictive validity. Psychological Bulletin, 136(6), 1092-1122. https://doi.org/10.1037/a0021212

Dahlsgaard, K., Peterson, C., \& Seligman, M. E. P. (2005). Shared virtue: The convergence of valued human strengths across culture and history. Review of General Psychology, 9(3), 203-213. https://doi.org/10.1037/1089-2680.9.3.203

Datu, J. A. D., \& Bernardo, A. B. I. (2020). The blessings of social-oriented virtues: Interpersonal character strengths are linked to increased life satisfaction and academic 
success among Filipino high school students. Social Psychological and Personality Science, 11(7), 983-990. https://doi.org/10.1177/1948550620906294

Donaldson, S. I., Dollwet, M., \& Rao, M. A. (2015). Happiness, excellence, and optimal human functioning revisited: Examining the peer-reviewed literature linked to positive psychology. The Journal of Positive Psychology, 10(3), 185-195. https://doi.org/10.1080/17439760.2014.943801

du Plessis, G. A., \& de Bruin, G. P. (2015). Using Rasch modelling to examine the international personality item pool (IPIP) values in action (VIA) measure of character strengths. Journal of Psychology in Africa, 25(6), 512-521. https://doi.org/10.1080/14330237.2015.1124603

Duan, W., \& Bu, H. (2017). Development and initial validation of a short three-dimensional inventory of character strengths. Quality of Life Research, 26(9), 2519-2531. https://doi.org/10.1007/s11136-017-1579-4

Duan, W., Ho, S. M. Y., Yu, B., Tang, X., Zhang, Y., Li, T., \& Yuen, T. (2012). Factor structure of the Chinese Virtues Questionnaire. Research on Social Work Practice, 22(6), 680-688. https://doi.org/10.1177/1049731512450074

Duan, W., Ho, S. M. Y., Bai, Y., \& Tang, X. (2013). Psychometric evaluation of the Chinese Virtues Questionnaire. Research on Social Work Practice, 23(3), 336-345. http://dx.doi.org/10.1177/1049731513477214

Eysenck, H. J. \& Eysenck, S. B. G. (1991). Manual of the Eysenck Personality Scales (EPQ adults). Hodder and Stoughton.

Flückiger, C., \& Beesdo-Baum, K. (2020). Ressourcenaktivierung [Resource activation]. In J. Hoyer \& S. Knappe (Eds.), Klinische Psychologie \& Psychotherapie [Clinal psychology \& psychotherapy] (pp. 575-588). Springer. https://doi.org/10.1007/978-3-662-61814- 
Freidlin, P., Littman-Ovadia, H., \& Niemiec, R. M. (2017). Positive psychopathology: Social anxiety via character strengths underuse and overuse. Personality and Individual Differences, 108, 50-54. https://doi.org/10.1016/j.paid.2016.12.003

Furnham, A., \& Lester, D. (2012). The development of a short measure of character strength. European Journal of Psychological Assessment, 28(2), 95-101. https://doi.org/10.1027/1015-5759/a000096

Gander, F., Hofmann, J., Proyer, R. T., \& Ruch, W. (2020). Character strengths - Stability, change, and relationships with well-being changes. Applied Research in Quality of Life, 15(2), 349-367. https://doi.org/10.1007/s11482-018-9690-4

Gander, F., Wagner, L., Amann, L., \& Ruch, W. (2021). What are character strengths good for? A daily diary study on character strengths enactment. The Journal of Positive Psychology. Advance online publication. https://doi.org/10.1080/17439760.2021.1926532

Giuliani, F., Ruch, W., \& Gander, F. (2020). Does the excellent enactment of highest strengths reveal virtues? Frontiers in Psychology, 11, 1545. https://doi.org/10.3389/fpsyg.2020.01545

Goldberg, L. R., Johnson, J. A., Eber, H. W., Hogan, R., Ashton, M. C., Cloninger, C. R., \& Gough, H. G. (2006). The international personality item pool and the future of publicdomain personality measures. Journal of Research in Personality, 40(1), 84-96. https://doi.org/10.1016/j.jrp.2005.08.007

Govindji, R. \& Linley, P.A. (2007). Strengths use, self-concordance and well-being: Implications for strengths coaching and coaching psychologists. International Coaching Psychology Review, 2(2), 143-153. 
Harzer, C., \& Ruch, W. (2013). The application of signature character strengths and positive experiences at work. Journal of Happiness Studies, 14(3), 965-983. https://doi.org/10.1007/s10902-012-9364-0

Harzer, C., \& Ruch, W. (2014). The role of character strengths for task performance, job dedication, interpersonal facilitation, and organizational support. Human Performance, 27(3), 183-205. https://doi.org/10.1080/08959285.2014.913592

Harzer, C., \& Ruch, W. (2016). Your strengths are calling: Preliminary results of a web-based strengths intervention to increase calling. Journal of Happiness Studies, 17(6), 22372256. https://doi.org/10.1007/s10902-015-9692-y

Hausler, M., Strecker, C., Huber, A., Brenner, M., Höge, T., \& Höfer, S. (2017). Distinguishing relational aspects of character strengths with subjective and psychological well-being. Frontiers in Psychology, 8, 1159. https://doi.org/10.3389/fpsyg.2017.01159

Heintz, S., \& Ruch, W. (2021). Cross-sectional age differences in 24 character strengths: Five meta-analyses from early adolescence to late adulthood. The Journal of Positive Psychology. Adavance online publication. https://doi.org/10.1080/17439760.2021.1871938

Ho, S. M. Y., Li, W. L., Duan, W., Siu, B. P. Y., Yau, S., Yeung, G., \& Wong, K. (2016). A Brief Strengths Scale for individuals with mental health issues. Psychological Assessment, 28(2), 147-157. https://doi.org/10.1037/pas0000164

Höfer, S., Hausler, M., Huber, A., Strecker, C., Renn, D., \& Höge, T. (2019). Psychometric characteristics of the German Values in Action Inventory of Strengths 120-Item Short Form. Applied Research in Quality of Life. https://doi.org/10.1007/s11482-018-9696-y Kachel, T., Huber, A., Strecker, C., Höge, T., \& Höfer, S. (2020). Development of cynicism in medical students: Exploring the role of signature character strengths and well-being. Frontiers in Psychology, 11, 328. https://doi.org/10.3389/fpsyg.2020.00328 
Kretzschmar, A., Harzer, C., \& Ruch, W. (2020). Character strengths in adults and adolescents: Their measurement and association with well-being. PsyArXiv. https://doi.org/10.31234/osf.io/caemw

Kretzschmar, A., Wagner, L., Gander, F., Hofmann, J., Proyer, R., \& Ruch, W. (2021). Character strengths and intelligence. PsyArXiv. https://doi.org/10.31234/osf.io/mh58j

Littman-Ovadia, H. (2015). Short form of the VIA Inventory of Strengths: Construction and initial tests of reliability and validity. International Journal of Humanities Social Sciences and Education, 2(4), 229-237.

Littman-Ovadia, H., Lazar-Butbul, V., \& Benjamin, B. A. (2014). Strengths-based career counseling: Overview and initial evaluation. Journal of Career Assessment, 22(3), 403419. https://doi.org/10.1177/1069072713498483

Luhmann, M., Necka, E. A., Schönbrodt, F. D., \& Hawkley, L. C. (2016). Is valuing happiness associated with lower well-being? A factor-level analysis using the Valuing Happiness Scale. Journal of Research in Personality, 60, 46-50. https://doi.org/10.1016/j.jrp.2015.11.003

Macdonald, C., Bore, M., \& Munro, D. (2008). Values in action scale and the Big 5: An empirical indication of structure. Journal of Research in Personality, 42(4), 787-799. https://doi.org/10.1016/j.jrp.2007.10.003

Mauss, I. B., Tamir, M., Anderson, C. L., \& Savino, N. S. (2011). Can seeking happiness make people unhappy? Paradoxical effects of valuing happiness. Emotion, 11(4), 807815. https://doi.org/10.1037/a0022010

McGrath, R. E. (2015). Integrating psychological and cultural perspectives on virtue: The hierarchical structure of character strengths. The Journal of Positive Psychology, 10(5), 407-424. https://doi.org/10.1080/17439760.2014.994222 
McGrath, R. E. (2019). The VIA Assessment Suite for adults: Development and initial evaluation (revised edition) [Technical report]. VIA Institute on Character.

McGrath, R. E., Brown, M., Westrich, B., \& Han, H. (2021). Representative sampling of the VIA Assessment Suite for adults. Journal of Personality Assessment. Advance online publication. https://doi.org/10.1080/00223891.2021.1955692

McGrath, R. E., Hall-Simmonds, A., \& Goldberg, L. R. (2020). Are measures of character and personality distinct? Evidence from observed-score and true-score analyses. Assessment, 27(1), 117-135. https://doi.org/10.1177/1073191117738047

McGrath, R. E., \& Wallace, N. (2021). Cross-validation of the VIA Inventory of StrengthsRevised and its short forms. Journal of Personality Assessment, 103(1), 120-131. https://doi.org/10.1080/00223891.2019.1705465

Miller, C. B. (2019). Some philosophical concerns about how the VIA classifies character traits and the VIA-IS measures them. The Journal of Positive Psychology, 14(1), 6-19. https://doi.org/10.1080/17439760.2018.1528377

Moreira, P. A. S., Inman, R. A., \& Cloninger, C. R. (2021). Virtues in action are related to the integration of both temperament and character: Comparing the VIA classification of virtues and Cloninger's biopsychosocial model of personality. The Journal of Positive Psychology. Advance online publication.

https://doi.org/10.1080/17439760.2021.1975158

Müller, S., \& Moshagen, M. (2019). Controlling for response bias in self-ratings of personality: A comparison of impression management scales and the overclaiming technique. Journal of Personality Assessment, 101(3), 229-236. https://doi.org/10.1080/00223891.2018.1451870

Niemiec, R. M. (2017). Character strengths interventions: A field guide for practitioners. Hogrefe Publishing. 
Ng, V., \& Tay, L. (2020). Lost in translation: The construct representation of character virtues. Perspectives on Psychological Science, 15(2), 309-326.

https://doi.org/10.1177/1745691619886014

Ng, V., Tay, L., \& Kuykendall, L. (2018). The development and validation of a measure of character: The CIVIC. The Journal of Positive Psychology, 13(4), 346-372. https://doi.org/10.1080/17439760.2017.1291850

Norrish, J. M., Williams, P., O’Connor, M., \& Robinson, J. (2013). An applied framework for Positive Education. International Journal of Wellbeing, 3(2), 147-161. https://internationaljournalofwellbeing.org/index.php/ijow/article/view/250

Park, N., \& Peterson, C. (2006a). Character strengths and happiness among young children: Content analysis of parental descriptions. Journal of Happiness Studies, 7, 323-341. https://doi.org/10.1007/s10902-005-3648-6

Park, N., \& Peterson, C. (2006b). Moral competence and character strengths among adolescents: The development and validation of the Values in Action Inventory of Strengths for Youth. Journal of Adolescence, 29, 891-909. https://doi.org/10.1016/j.adolescence.2006.04.011

Partsch, M. V., Bluemke, M., \& Lechner, C. M. (2021). Revisiting the hierarchical structure of the 24 VIA character strengths: Three global dimensions may suffice to capture their essence. European Journal of Personality. Advance online publication. https://doi.org/10.1177/08902070211017760

Peterson, C., \& Seligman, M. (2004). Character strengths and virtues: A handbook and classification. Oxford University Press.

Proyer, R. T., Gander, F., Wellenzohn, S., \& Ruch, W. (2015). Strengths-based positive psychology interventions: A randomized placebo-controlled online trial on long-term 
effects for a signature strengths- vs. a lesser strengths-intervention. Frontiers in Psychology, 6, 456. https://doi.org/10.3389/fpsyg.2015.00456

Ruch, W., Gander, F., Wagner, L., \& Giuliani, F. (2021). The structure of character: On the relationships between character strengths and virtues. The Journal of Positive Psychology, 16(1), 116-128. https://doi.org/10.1080/17439760.2019.1689418

Ruch, W., Heintz, S., \& Wagner, L. (2020). Co-occurrence patterns of character strengths and measured core virtues in German-speaking adults. Frontiers in Psychology, 11, 599094. https://doi.org/10.3389/fpsyg.2020.599094

Ruch, W., Martínez-Martí, M. L., Proyer, R. T., \& Harzer, C. (2014). The Character Strengths Rating Form (CSRF): Development and initial assessment of a 24-item rating scale to assess character strengths. Personality and Individual Differences, 68, 53-58. https://doi.org/10.1016/j.paid.2014.03.042

Ruch, W., Niemiec, R. M., McGrath, R. E., Gander, F., \& Proyer, R. T. (2020). Character strengths-based interventions: Open questions and ideas for future research. The Journal of Positive Psychology, 15(5), 680-684. https://doi.org/10.1080/17439760.2020.1789700

Ruch, W., Platt, T., \& Hofmann, J. (2014). The character strengths of class clowns. Frontiers in Psychology, 5, 1075. https://doi.org/10.3389/fpsyg.2014.01075

Ruch, W., \& Proyer, R. T. (2015). Mapping strengths into virtues: The relation of the 24 VIAstrengths to six ubiquitous virtues. Frontiers in Psychology, 6, 460. https://doi.org/10.3389/fpsyg.2015.00460

Ruch, W., Proyer, R. T., Harzer, C., Park, N., Peterson, C., \& Seligman, M. E. P. (2010). Values in Action Inventory of Strengths (VIA-IS): Adaptation and validation of the German version and the development of a peer-rating form. Journal of Individual Differences, 31, 138-149. https://doi.org/10.1027/1614-0001/a000022 
Ruch, W., Proyer, R. T., \& Weber, M. (2010). Humor as a character strength among the elderly: Empirical findings on age-related changes and its contribution to satisfaction with life. Zeitschrift für Gerontologie und Geriatrie, 43(1), 13-18. https://doi.org/10.1007/s00391-009-0090-0

Ruch, W., \& Stahlmann, A. G. (2019). 15 years after Peterson and Seligman (2004): A brief narrative review of the research on the 12 criteria for character strengths - the forgotten treasure of the VIA classification. In M. Brohm-Badry, C. Peifer, J. M. Greve, \& B. Berend (Eds.), Zusammen wachsen - Förderung der positiv-psychologischen Entwicklung von Individuen, Organisationen und Gesellschaft (pp. 142-172). Pabst Science Publishers.

Ruch, W., Weber, M., Park, N., \& Peterson, C. (2014). Character strengths in children and adolescents: Reliability and initial validity of the German Values in Action Inventory of Strengths for Youth (German VIA-Youth). European Journal of Psychological Assessment, 30, 57-64. https://doi.org/10.1027/1015-5759/a000169

Seligman, M. E. P. (2015). Chris Peterson's unfinished masterwork: The real mental illnesses. The Journal of Positive Psychology, 10(1), 3-6. https://doi.org/10.1080/17439760.2014.888582

Seligman, M. E. P., Steen, T. A., Park, N., \& Peterson, C. (2005). Positive psychology progress: Empirical validation of interventions. American Psychologist, 60(5), 410-421. https://doi.org/10.1037/0003-066X.60.5.410

Shoshani, A. (2019). Young children's character strengths and emotional well-being: Development of the Character Strengths Inventory for Early Childhood (CSI-EC). The Journal of Positive Psychology, 14, 86-102. https://doi.org/10.1080/17439760.2018.1424925 
Shoshani, A., \& Shwartz, L. (2018). From character strengths to children's well-being: Development and validation of the Character Strengths Inventory for Elementary School Children. Frontiers in Psychology, 9, 2123. https://doi.org/10.3389/fpsyg.2018.02123

Stahlmann, A. G., \& Ruch, W. (2020). Scrutinizing the criteria for character strengths: Laypersons assert that every strength is positively morally valued, even in the absence of tangible outcomes. Frontiers in Psychology, 11, 591028. https://doi.org/10.3389/fpsyg.2020.591028

Toback, R. L., Graham-Bermann, S. A., \& Patel, P. D. (2016). Outcomes of a character strengths-based intervention on self-esteem and self-efficacy of psychiatrically hospitalized youths. Psychiatric Services, 67(5), 574-577. https://doi.org/10.1176/appi.ps.201500021

van Zyl, L. E., Arijs, D., Cole, M. L., Gliíska-Newes, A., Roll, L. C., Rothmann, S., Shankland, R., Stavros, J. M., \& Verger, N. B. (2021). The Strengths Use Scale: Psychometric properties, longitudinal invariance and criterion validity. Frontiers in Psychology, 12, 2135. https://doi.org/10.3389/fpsyg.2021.676153

Vanhove, A. J., Harms, P. D., \& DeSimone, J. A. (2016). The Abbreviated Character Strengths Test (ACST): A preliminary assessment of test validity. Journal of Personality Assessment, 98(5), 536-544. https://doi.org/10.1080/00223891.2016.1148044

Vylobkova, V., Heintz, S., Gander, F., Wagner, L., \& Ruch, W. (2021). Convergence and psychometric properties of character strengths measures: The VIA-IS and the VIA-IS-R. PsyArXiv. https://doi.org/10.31234/osf.io/8zvjb

Wagner, L. (2019). Good character is what we look for in a friend: Character strengths are positively related to peer acceptance and friendship quality in early adolescents. The Journal of Early Adolescence, 39(6), 864-903. https://doi.org/10.1177/0272431618791286 
Wagner, L., Gander, F., Proyer, R. T., \& Ruch, W. (2020). Character strengths and PERMA: Investigating the relationships of character strengths with a multidimensional framework of well-Being. Applied Research in Quality of Life, 15(2), 307-328. https://doi.org/10.1007/s11482-018-9695-Z

Wagner, L., Holenstein, M., Wepf, H., \& Ruch, W. (2020). Character strengths are related to students' achievement, flow experiences and enjoyment in teacher-centered learning, individual, and group work above the influence of cognitive ability. Frontiers in Psychology, 11, 1324. https://doi.org/10.3389/fpsyg.2020.01324

Wagner, L., Pindeus, L., \& Ruch, W. (2021). Character strengths in the life domains of work, education, leisure, and relationships, and their associations with flourishing. Frontiers in Psychology, 12, 597534. https://doi.org/10.3389/fpsyg.2021.597534

Wagner, L., \& Ruch, W. (2021). Displaying character strengths in behavior is related to wellbeing and achievement at school: Evidence from between- and within-person analyses. PsyArXiv. https://doi.org/10.31234/osf.io/bphrk

Wiese, C. W., Tay, L., Duckworth, A. L., D’Mello, S., Kuykendall, L., Hofmann, W., Baumeister, R. F., \& Vohs, K. D. (2018). Too much of a good thing? Exploring the inverted-U relationship between self-control and happiness. Journal of Personality, 86(3), 380-396. https://doi.org/10.1111/jopy.12322

Zettler, I., Hilbig, B. E., Moshagen, M., \& de Vries, R. E. (2015). Dishonest responding or true virtue? A behavioral test of impression management. Personality and Individual Differences, 81, 107-111. https://doi.org/10.1016/j.paid.2014.10.007 